\title{
CLASSES FONOLÓGICAS E ORTOGRAFIA INFANTIL
}

\section{PHONOLOGICAL CLASSES AND CHILDREN'S ORTHOGRAPHY}

\author{
Lourenço Chacon (UNESP) ${ }^{1}$ \\ Suellen Vaz (UNESP) $)^{2}$ \\ Larissa Paschoal (UNESP) $)^{3}$ \\ Isabela de Oliveira Pezarini (UNESP) ${ }^{4}$
}

\section{RESUMO}

A proposta mais geral do presente trabalho é verificar em que medida aspectos das diferentes classes fonológicas estão relacionados a pontos de maior facilidade ou dificuldade na ortografia infantil. Para verificar os efeitos dessa relação, o desenvolvimento do trabalho foi orientado pelos seguintes objetivos: (1) descrever o desempenho ortográfico de crianças quanto ao registro de consoantes do Português Brasileiro; (2) verificar se o acento influencia a ocorrência de erros no interior das palavras; e (3) caracterizar o padrão da distribuição dos erros. Os dados foram extraídos de 866 textos de 76 crianças que, em 2001 e 2002, frequentavam a primeira e a segunda série do ensino fundamental de uma escola pública de um município do interior paulista. Todos os

1 Doutor em Linguística; Universidade Estadual Paulista (UNESP); Avenida Hygino Muzzi Filho, 737, CEP 17525-000 - Marília (SP); fone: (14) 3402-1324; e-mail: lourencochacon@ yahoo.com.br

2 Doutoranda em Linguística; Programa de Pós-Graduação em Estudos Linguísticos do Instituto de Biociências, Letras e Ciências Exatas da Universidade Estadual Paulista (IBILCE/UNESP); Rua Cristóvão Colombo, 2265, CEP 15054-000 - São José do Rio Preto(SP); fone: (17) 3221-2444; e-mail: suelvaz@hotmail.com

3 Mestranda em Fonoaudiologia; Programa de Pós-Graduação em Fonoaudiologia da Faculdade de Filosofia e Ciências da Universidade Estadual Paulista (UNESP); Avenida Hygino Muzzi Filho, 737, CEP 17525-000 - Marília (SP); fone: (14) 3402-1336; e-mail: larissa. apaschoal@gmail.com

4 Mestranda em Fonoaudiologia; Programa de Pós-Graduação em Fonoaudiologia da Faculdade de Filosofia e Ciências da Universidade Estadual Paulista (UNESP); Avenida Hygino Muzzi Filho, 737, CEP 17525-000 - Marília (SP); fone: (14) 3402-1336; e-mail: isabela.pezarini@gmail.com 
grafemas que remetiam às classes das consoantes oclusivas, fricativas e soantes, situados no ataque silábico simples, foram classificados em acertos e erros. Em seguida, os erros foram organizados conforme ocorressem em sílabas acentuadas, ou não. Posteriormente, foram distribuídos em categorias que os organizavam conforme correspondessem a omissões, substituições ortográficas não-fonológicas, substituições ortográficas fonológicas e híbridos. Como resultados, verificou-se que: (a) os acertos predominaram sobre os erros; (b) a quantidade de erros, bem como seus diferentes tipos, variaram em função da classe fonológica a que remetiam; e (c) os erros não sofreram influência direta do acento. Esses resultados apontam para uma alta estabilidade na aquisição da escrita - portanto, para o sucesso de práticas de letramento que favorecem a alfabetização. Apontam, também, para relações não-simétricas entre características das classes fonológicas e a ortografia das diferentes classes - não-simetria que chama a atenção para os diferentes estatutos que tanto erros quanto acertos podem adquirir na aquisição da ortografia.

PALAVRAS CHAVE: aquisição da escrita; ortografia.

\section{ABSTRACT}

The general purpose of this paper is to assess in which level the aspects of different phonological classes are connected to the points of greater ease or difficulty in children's orthography. In order to verify the impact of this relationship, this paper was guided by the following goals: (1) to describe children's orthographic performance regarding consonant registers in Brazilian Portuguese; (2) to verify if stress can influence the occurrence of errors in these words; and (3) to describe the pattern of errors distribution. Data were extracted from 866 texts of 76 children who, in 2001 and 2002, attended first and second year in a public elementary school from a townin São Paulo state. All graphemes referred to occlusive, fricative and sonorant consonants present in simple syllable onset, were classified in hits and errors. Then, errors were divided according to its occurrence in stressed or non-stressed syllables. After that, they were categorized in the following cases: omissions, nonphonological orthographic substitutions, phonological orthographic 
substitutions and hybrids. It was found that:(a) hits outweighed errors; (b) the amount of errors, as well as their different types, vary according to the phonological class which it referred to; and (c) errors were not under direct influence of the stress. These results indicate solid stability in writing acquisition - thereafter, the success of literacy practices, which foment alphabetization. They also point to non-symmetrical relationship between the characteristics of phonological classes and orthography of different classes - this non-symmetry draws the attention to the different status that errors and hits alike may get during orthography acquisition.

KEYWORDS: writing acquisition; orthography.

\section{INTRODUÇÃO}

Muito se pode dizer da escrita, como se pode depreender do fragmento de texto que se segue, extraído de uma dissertação de mestrado:

Vale salientar que as hesitações são diferentemente caracterizadas nessas duas tendências de trabalhos. Na primeira, a hesitação remeteria a uma pausa curta de 1 a 2 segundos (...) e caracterizaria a tipologia de disfluências tidas como comuns a todos os falantes. Nessa perspectiva existe, portanto, a distinção entre hesitações, pausas e alongamentos. Já na segunda, a hesitação seria um fenômeno que engloba pausas silenciosas, pausas preenchidas, alongamentos, repetições, gaguejamentos e cortes bruscos presentes no que a primeira tendência classifica como disfluências. Será essa a perspectiva assumida em nosso trabalho, já que (...) interpretaremos as hesitações sob um ponto de vista linguístico-discursivo, segundo o qual a hesitação, independentemente de diferenciar uma condição normal de uma condição patológica, é constitutiva do exercício da linguagem (VILLEGA, 2014, P, 12).

Já de início, é possível dizer que essa escrita se mostra como um ato enunciativo, no sentido benvenisteano da palavra, uma vez que se detectam nela marcas do aparelho formal da enunciação, sobretudo as de (primeira) pessoa. Na organização dessa escrita, um primeiro tipo de arranjo se faz mostrar. Nesse arranjo, a recuperação de fatos das condições 
: de produção dessa escrita - como, por exemplo, o de se tratar de uma dissertação de mestrado no campo da Fonoaudiologia - permite localizar no texto características pragmáticas e discursivas bem específicas. Com efeito, ele foi produzido no interior de uma prática de letramento determinada, de natureza acadêmica, como requisito para a obtenção do título de mestre nesse campo do conhecimento - o que chama a atenção para suas características pragmáticas. Mas mesmo nesse pequeno excerto do texto original se pode depreender uma polêmica (a disputa pelo sentido do que se poderia caracterizar como hesitação) e de um posicionamento do autor em relação a essa polêmica - o que chama a atenção para suas características discursivas.

Porém, além desse tipo de arranjo (que poderíamos definir como pragmático-discursivo) na organização da escrita em consideração, outro tipo de arranjo - de natureza distinta, mas estreitamente vinculado ao primeiro - também chama a atenção em sua organização. Com efeito, mostram-se nessa escrita mecanismos de coesão e de coerência textual, estruturação morfossintática característica de uma escrita formal culta, ancoragem em características fonológicas da língua, tanto em sua dimensão prosódica (como o atestam, por exemplo, os sinais de pontuação e os acentos ortográficos) quanto em sua dimensão segmental (como o atesta, sobretudo, uma correspondência grafema/fonema de acordo com as convenções ortográficas).

Em síntese, o que se pode depreender desse excerto de uma dissertação permitiria dizer que aescrita é um modo de enunciação da língua, que circula socialmente em diferentes práticas de letramento, e cuja organização supõe dois tipos principais de arranjos:

(1) aqueles de natureza pragmático-discursiva - voltados prioritariamente ao atendimento de demandas sociais que regulam a circulação da escrita; e

(2) aqueles de natureza linguístico-textual - voltados prioritariamente ao atendimento de demandas diretamente envolvidas com o funcionamento da língua.

Esta é a concepção de escrita subjacente à investigação cujos resultados serão expostos no presente artigo. No entanto, como abordar 
a complexidade desses arranjos, bem como sua relação, alargariam em muito o alcance do artigo, um recorte bem específico norteou sua elaboração. Vamos, então, nos restringir aos aspectos fonológicos (dos arranjos linguístico-textuais) dos exemplares de escrita que analisamos. No interior desse recorte, outra delimitação se fará: nossa atenção se voltará exclusivamente aos aspectos fonológicos relacionados à ortografia.

$\mathrm{Na}$ literatura nacional que tem se voltado para a ortografia na escrita infantil, vários tipos de questões tem sido levantados. Destacamse, dentre outras, questões como: (1) a de seus desvios (CAPELLINI ET AL, 2011; ROSA, GOMES, PEDROSO, 2012; CAPELLINI ET AL, 2012); (2) a de seu papel em tarefas de leitura, de escrita e do que se tem caracterizado como consciência fonológica (PAOLUCCI, ÁVILA, 2009; NUNES, FROTA, MOUSINHO, 2009; FERREIRA, CORREA, 2010; PONTES, DINIZ, MARTINS-REIS, 2013); (3) a de sua importância em programas fonoaudiológicos voltados ao letramento de escolares (BRITO, 2010; CÁRNIO, 2011); (4) a de seu aspecto indiciáriodas relações entre o escrevente e a linguagem (MACHADO, BERBERIAN, SANTANA, 2009; MASSI ET AL., 2009); e (5) a de sua estreita relação com aspectos fonéticofonológicos da linguagem (ADAMOLI, MIRANDA, 2009; MIRANDA, MATZENAUER, 2010; TEIXEIRA ET AL., 2011; CHACON, 2008; CARDOSO ET AL., 2010; BERTI, CHACON, SANTOS, 2010; KOMESU, TENANI, 2010; CHACON, BERTI, BURGEMEISTER, 2011; AMARAL ET AL., 2011; TENANI, REIS, 2011; CAMPOS, TENANI, BERTI, 2011; SCHIER, BERTI, CHACON, 2013; CHACON, VAZ, 2013.)

Embora bastante rica e diversificada, não encontramos nessa literatura - até onde nosso levantamento bibliográfico conseguiu alcançar - trabalhos que se voltassem direta e exclusivamente ao desempenho ortográfico infantil, no que se refere à relação entre esse desempenho e todas as classes fonológicas do português. É justamente esta a proposta do presente artigo, sobretudo em função de questões que essa literatura tem permitido suscitar, mas para as quais não tem fornecido, até o presente momento, respostas mais precisas. Trata-se, por exemplo: de questões como: (a) a relação entre acertos e erros ortográficos, na escrita infantil, varia segundo a classe fonológica envolvida na correspondência grafema/ fonema?; (2) o contraste entre sílabas acentuadas e não acentuadas é um 
: fator que (des)favorece a ocorrência de erros ortográficos?; e, finalmente,

: (3) no que concerne mais diretamente aos erros, seu tipo e sua incidência também sofrem, ou não, influência da classe fonológica envolvida na correspondência grafema/fonema?.

$\mathrm{Na}$ busca de resposta a essas questões, a investigação cujos resultados se mostrarão no presente artigo foi orientada pelos seguintes objetivos:

(1) descrever o desempenho ortográfico de crianças quanto ao registro de consoantes do Português Brasileiro;

(2) verificar se o acento influencia a ocorrência de erros no interior das palavras; e

(3) caracterizar o padrão da distribuição dos erros.

Um esclarecimento deve ser feito a propósito do que vimos denominando como acertos e como erros. Para nós, acertos nem sempre significam ou podem ser vistos como índices de conhecimento - de fato, muitas vezes, sobretudo na escrita inicial de crianças, o que se mostra como acerto pode ser fruto do acaso ou da memória visual de palavras ou de estruturas linguísticas, sem análise, por parte da criança, dos vínculos entre os grafemas e os fonemas que a eles correspondem na escrita dessas palavras ou estruturas. Analogamente, o erro não significa nem pode ser visto como índice de ausência de conhecimento - já que, como procuraremos demonstrar, raramente ele foge a algo que, de certo modo, não seja suscitado pela própria língua ou pelas regras que orientam a correspondência grafema/fonema.

Feitos esses esclarecimentos passemos à descrição dos aspectos metodológicos de nossa investigação.

\section{Metodologia}

Os dados utilizados foram extraídos de um conjunto de produções textuais que compõem um banco de dados do Grupo de Pesquisa "Estudos sobre a linguagem" (GPEL/CNPq). Esse banco é parte integrante do projeto Vínculos entre características de práticas orais e letradas na aquisição e desenvolvimento da escrita (CNPq - Processo 400183/2009-9), aprovado pelo Comitê de Ética em Pesquisa da FFC/Unesp sob número 0132/2010. 
O banco é composto por produções textuais de crianças que cursavam o Ensino Fundamental I (EF I), entre 2001 e 2004, em duas : escolas públicas do município de São José do Rio Preto (SP). Essas produções são referentes a diferentes propostas temáticas que, ao longo do período letivo, foram apresentadas em sala de aula por pesquisadores do GPEL, aproximadamente, a cada quinze dias.

Como critérios de inclusão para a elaboração do banco - mediante a assinatura de um Termo de Consentimento Livre e Esclarecido -, foram consideradas somente as produções realizadas por crianças que não apresentavam queixas de distúrbios de aprendizagem ou de desenvolvimento de linguagem.

Do material que compõe o banco, foram selecionadas produções textuais de 76 crianças que cursaram a $1^{\circ}$ série do EF I, de ambas as escolas - produções que se referem a 14 diferentes propostas temáticas. Do total de 1.064 produções esperadas (76 crianças x 14 propostas temáticas), devido a ausências de algumas crianças ou à impossibilidade de interpretação de (seus) registros escritos, o número de produções analisadas variou de acordo com as classes consonantais, como se observa no quadro a seguir:

Quadro 1.Produções analisadas

\begin{tabular}{|c|c|c|c|}
\hline Classes Consonantais & Ausências & Descartes & $\begin{array}{c}\text { Producões } \\
\text { analisadas }\end{array}$ \\
\hline Fricativas & 198 & 104 & $\mathbf{7 6 2}$ \\
\hline Oclusivas & 198 & 27 & $\mathbf{8 3 9}$ \\
\hline Soantes & 198 & $\mathbf{6 5}$ & $\mathbf{8 0 1}$ \\
\hline
\end{tabular}

Nas produções resultantes após os descartes, foram analisadas todas as possibilidades de ocorrências de grafemas que remetiam a fonemas das três classes consonantais do Português Brasileiro (PB) investigadas para o presente artigo: oclusivas, fricativas e soantes.

\subsection{Forma de análise dos resultados}

Para descrever a maneira como os resultados foram analisados, serão retomados os objetivos que nortearam o seu desenvolvimento.

No que se refere ao primeiro objetivo (descrever o desempenho ortográfico de crianças quanto ao registro de consoantes do $\mathrm{PB}$ ), foram adotados como critérios de análise desse desempenho o levantamento 
de: (a) acertos - quando o registro das consoantes estava de acordo com : as convenções ortográficas do PB; e (b) erros - quando o registro das consoantes estava em desacordo com as convenções ortográficas do PB.

No que se refere ao segundo objetivo (verificar se o acento influencia a ocorrência de erros no interior das palavras), os erros foram distribuídos em dois grandes grupos conforme ocorressem em: (a) sílabas não acentuadas - pretônicas, postônicas e monossílabos átonos; e (b) sílabas acentuadas tônicas e monossílabos tônicos.

Por fim, no que se refere ao terceiro objetivo (caracterizar o padrão da distribuição dos erros), distribuíram-se os erros em quatro categorias principais: (a) OMISSÕES ORTOGRÁFICAS - não registro da consoante alvo, como, por exemplo, a palavra "minha" registrada como "mia”; (b) SUBSTITUIÇÕES ORTOGRÁFICAS NÃO FONOLÓGICAS - substituições que não alteraram o valor fonológico da palavra, como, por exemplo, a palavra "caçador" registrada como "cassador"; (c) SUBSTITUIÇÕES ORTOGRÁFICAS FONOLÓGICAS - substituições que alteraram o valor fonológico da palavra, como, por exemplo, a palavra "laringe" registrada como "naringe"; e (d) SUBSTITUIÇÕES ORTOGRÁFICAS HÍBRIDAS - substituições que alteraram o valor fonológico da palavra, porém, envolveram grafemas que dependiam de regras contextuais para o registro ortográficodo fonema, como, por exemplo, a palavra "aquela" registrada como "acela"5.

\subsection{Análise estatística}

Realizaram-se análises descritiva e inferencial dos dados com o uso do softwar estatistica (versão 7.0). Para a análise descritiva dos dados, foram utilizadas duas medidas de tendência central (média e mediana) e uma medida de dispersão (desvio padrão). Já para a análise inferencial, foram utilizados os testes não paramétricos Friedman ANOVA and Kendall Coeff. of Concordancee Sign Test para variáveis dependentes. A escolha dos testes não paramétricos baseou-se na verificação da violação da curva do teste de normalidade Shapiro-Wilk, adotando-se o valor do nível de significância ( ) 0,05.

5 Relembre-se que o fonema $/ \mathrm{k} /$ pode ser registrado ortograficamente por $\{\mathrm{c}\}$ apenas diante das vogais $\{a, o, u\}$. 


\section{Resultados}

Os resultados serão dispostos de acordo com os objetivos do presente estudo.

Para o primeiro objetivo, foi encontrado um total de 12.617 possibilidades de registro de consoantes soantes, 21.049 possibilidades de registro de consoantes oclusivas e 9.396 possibilidades de registro de consoantes fricativas. Essas possibilidades resultaram em registros caracterizados como acertos e como erros, cujos valores estão expostos, respectivamente, nas Tabelas 1 e 2 :

Tabela 1. Ocorrências de acertos no interior das classes

\begin{tabular}{ccccccc}
\hline Classes & $\begin{array}{c}\text { Número de } \\
\text { ocorrências }\end{array}$ & Média & Mediana & $\begin{array}{c}\text { Desvio } \\
\text { padrão }\end{array}$ & $\begin{array}{c}\text { Sum } \\
\text { ofRank }\end{array}$ & $\begin{array}{c}\text { Friedman } \\
\text { ANOVA and } \\
\text { Kendall Coeff. } \\
\text { ofConcordance }\end{array}$ \\
\hline Fricativas & 7.885 & 563,21 & 517,00 & 263,70 & 16 & $\begin{array}{c}\text { ANOVA Chi } \\
\text { Sqr. }=24,57\end{array}$ \\
Oclusivas & 20.318 & 1451,29 & 1408,50 & 596,52 & 42 & $\mathrm{p}=0,00$ \\
Soantes & 11.917 & 563,21 & 775,00 & 381,10 & 26 & $\mathrm{df}=2$ \\
\hline
\end{tabular}

Fonte: Dados da pesquisa. Teste: Friedman ANOVA and Kendall Coeff. ofConcordance( 0,05$)$

Tabela 2. Ocorrências de erros no interior das classes

\begin{tabular}{ccccccc}
\hline Classes & $\begin{array}{c}\text { Número de } \\
\text { ocorrências }\end{array}$ & Média & Mediana & $\begin{array}{c}\text { Desvio } \\
\text { padrão }\end{array}$ & $\begin{array}{c}\text { Sum } \\
\text { ofRank }\end{array}$ & $\begin{array}{c}\text { Friedman } \\
\text { ANOVA and } \\
\text { Kendall Coeff. } \\
\text { ofConcordance }\end{array}$ \\
\hline Fricativas & 1511 & 107,93 & 99,50 & 46,26 & 41 & $\begin{array}{c}\text { ANOVA Chi } \\
\text { Sqr. }=19,00\end{array}$ \\
Oclusivas & 731 & 52,21 & 49,00 & 21,27 & 24 & $\mathrm{p}=0,00$ \\
Soantes & 700 & 50,00 & 47,00 & 30,04 & 19 & $\mathrm{df}=2$ \\
\hline
\end{tabular}

Fonte: Dados da pesquisa. Teste: Friedman ANOVA and Kendall Coeff. ofConcordance $(0,05)$

$\mathrm{Na}$ distribuição dos acertos, de acordo com a Tabela 1, os grafemas que remetiam às consoantes oclusivas foram os que apresentaram maior número de ocorrências, seguidos daqueles que remetiam às consoantes soantes e, por fim, às consoantes fricativas. Já na distribuição de erros, como 
se observa na Tabela 2 , os grafemas que remetiam às consoantes fricativas : foram os que apresentaram maior número de ocorrências, seguidos dos que remetiam às consoantes oclusivas e, por fim, às consoantes soantes. Observa-se, também, que o teste estatístico inferencial apresentou diferença significativa, indicando que a distribuição dos acertos e dos erros não ocorreu de maneira aleatória.

É possível observar, ainda, nos resultados apresentados, maior quantidade de acertos quando comparada à dos erros no interior de todas as três classes analisadas - quantidade esta que se mostrou estatisticamente significativa pelo Sign Test (Fricativas Z=3,47; p=0,00 / Oclusivas Z=3,47; $\mathrm{p}=0,00 /$ Soantes $\mathrm{Z}=3,47 ; \mathrm{p}=0,00$ ).

Para o segundo objetivo, os erros foram organizados conforme ocorressem em sílabas acentuadas e em sílabas não acentuadas. Os resultados estão expostos nas Tabelas 3 e 4:

Tabela 3. Distribuição dos erros em sílabas acentuadas

\begin{tabular}{ccccccc}
\hline Classes & $\begin{array}{c}\text { Número de } \\
\text { ocorrências }\end{array}$ & Média & Mediana & $\begin{array}{c}\text { Desvio } \\
\text { padrão }\end{array}$ & $\begin{array}{c}\text { Sum } \\
\text { ofRank }\end{array}$ & $\begin{array}{c}\text { Friedman } \\
\text { ANOVA and } \\
\text { Kendall Coeff. } \\
\text { ofConcordance }\end{array}$ \\
\hline Fricativas & 685 & 48,93 & 41,00 & 26,92 & 42 & $\begin{array}{c}\text { ANOVA Chi } \\
\text { Sqr. }=22,37\end{array}$ \\
Oclusivas & 289 & 20,64 & 17,50 & 11,80 & 23 & $\mathrm{p}=0,00$ \\
Soantes & 258 & 18,43 & 16,00 & 11,21 & 19 & $\mathrm{df}=2$ \\
\hline
\end{tabular}

Fonte: Dados da pesquisa. Teste: Friedman ANOVA and Kendall Coeff. ofConcordance $(0,05)$

Tabela 4. Distribuição dos erros em sílabas não acentuadas

\begin{tabular}{ccccccc}
\hline Classes & $\begin{array}{c}\text { Número de } \\
\text { ocorrências }\end{array}$ & Média & Mediana & $\begin{array}{c}\text { Desvio } \\
\text { padrão }\end{array}$ & $\begin{array}{c}\text { Sum } \\
\text { ofRank }\end{array}$ & $\begin{array}{c}\text { Friedman } \\
\text { ANOVA and } \\
\text { Kendall Coeff. } \\
\text { ofConcordance }\end{array}$ \\
\hline Fricativas & 826 & 59,00 & 56,50 & 25,06 & 39 & $\begin{array}{c}\text { ANOVA Chi Sqr. } \\
=13,00\end{array}$ \\
Oclusivas & 442 & 31,57 & 31,00 & 12,93 & 23 & $\mathrm{p}=0,00$ \\
Soantes & 442 & 31,57 & 26,00 & 21,05 & 22 & $\mathrm{df}=2$ \\
\hline
\end{tabular}

Fonte: Dados da pesquisa. Teste: Friedman ANOVA and Kendall Coeff. ofConcordance $(0,05)$ 
De acordo com a Tabela 3, observa-se maior número de erros em sílabas acentuadas nos grafemas que remetiam às consoantes fricativas, : seguidos dos que remetiam às oclusivas e, então, às soantes. Da mesma forma, de acordo com a Tabela 4, o maior número de erros em sílabas não acentuadas foi observado nos grafemas que remetiam às consoantes fricativas, seguidos daqueles que remetiam às oclusivas e às soantes. Observa-se, também, que o teste inferencial mostrou que a distribuição dos erros entre as classes não se deu de maneira aleatória, tanto em sílabas acentuadas quanto em sílabas não acentuadas.

Por fim, observa-se maior quantidade de erros em sílabas nãoacentuadas nas três classes consonantais; porém, de acordo com o Sign Test, a diferença foi estatisticamente significativa apenas nas consoantes oclusivas e soantes (Fricativas $Z=1,33 ; p=0,18$ / Oclusivas $Z=2,22 ; p=0,03$ / Soantes $Z=2,41 ; p=0,01)$.

Finalmente, para o terceiro objetivo, os erros foram categorizados em: substituições ortográficas não fonológicas; substituições ortográficas fonológicas; substituições ortográficas híbridas; e omissões. Os resultados estão dispostos nas tabelas 5, 6, 7 e 8:

Tabela 5. Distribuição das substituições ortográficas não fonológicas

\begin{tabular}{ccccccc}
\hline Classes & $\begin{array}{c}\text { Número de } \\
\text { ocorrências }\end{array}$ & Média & Mediana & $\begin{array}{c}\text { Desvio } \\
\text { padrão }\end{array}$ & $\begin{array}{c}\text { Sum } \\
\text { ofRank }\end{array}$ & $\begin{array}{c}\text { Friedman } \\
\text { ANOVA and } \\
\text { Kendall Coeff. } \\
\text { ofConcordance }\end{array}$ \\
\hline Fricativas & 705 & 50,36 & 47,50 & 21,93 & 41,00 & $\begin{array}{c}\text { ANOVA Chi Sqr. } \\
=22,07\end{array}$ \\
Oclusivas & 93 & 6,64 & 6,00 & 3,39 & 26,50 & $\mathrm{p}=0,00$ \\
Soantes & 29 & 2,07 & 1,00 & 2,87 & 16,50 & $\mathrm{df}=2$ \\
\hline
\end{tabular}

Fonte: Dados da pesquisa. Teste: Friedman ANOVA and Kendall Coeff. ofConcordance $(0,05)$

Em relação às substituições ortográficas não fonológicas, de acordo com a Tabela 5, essas foram mais frequentes nos grafemas que remetiam às consoantes fricativas, seguidos dos que remetiam às oclusivas e, por fim, às soantes. 
Tabela 6. Distribuição das substituições ortográficas fonológicas

\begin{tabular}{ccccccc}
\hline Classes & $\begin{array}{c}\text { Número de } \\
\text { ocorrências }\end{array}$ & Média & Mediana & $\begin{array}{c}\text { Desvio } \\
\text { padrão }\end{array}$ & $\begin{array}{c}\text { Sum } \\
\text { ofRank }\end{array}$ & $\begin{array}{c}\text { Friedman } \\
\text { ANOVA and } \\
\text { Kendall Coeff. } \\
\text { ofConcordance }\end{array}$ \\
\hline Fricativas & 176 & 12,43 & 10,00 & 21,93 & 15,00 & $\begin{array}{c}\text { ANOVA Chi } \\
\text { Sqr. }=19,74\end{array}$ \\
Oclusivas & 298 & 21,29 & 19,00 & 3,39 & 31,50 & $\mathrm{p}=0,00$ \\
Soantes & 365 & 26,07 & 23,00 & 12,95 & 37,50 & $\mathrm{df}=2$ \\
\hline
\end{tabular}

Fonte: Dados da pesquisa. Teste: Friedman ANOVA and Kendall Coeff. ofConcordance $(0,05)$

Já em relação às substituições ortográficas fonológicas, cujos resultados são apontados na Tabela 6, essas foram mais frequentes nos grafemas que remetiam às consoantes soantes, seguidos dos que remetiam às oclusivas e, por fim, às fricativas.

Tabela 7. Distribuição das substituições ortográficas híbridas

\begin{tabular}{ccccccc}
\hline & $\begin{array}{c}\text { Número de } \\
\text { ocorrências }\end{array}$ & Média & Mediana & $\begin{array}{c}\text { Desvio } \\
\text { padrão }\end{array}$ & $\begin{array}{c}\text { Sum } \\
\text { ofRank }\end{array}$ & $\begin{array}{c}\text { Friedman } \\
\text { ANOVA and } \\
\text { Kendall Coeff. } \\
\text { ofConcordance }\end{array}$ \\
\hline Fricativas & 646 & 46,29 & 43,00 & 26,23 & 42,00 & $\begin{array}{c}\text { ANOVA Chi Sqr. } \\
=21,70\end{array}$ \\
Oclusivas & 132 & 9,43 & 7,00 & 8,90 & 22,50 & $\mathrm{p}=0,00$ \\
Soantes & 152 & 10,86 & 5,00 & 14,13 & 19,50 & $\mathrm{df}=2$ \\
\hline
\end{tabular}

Fonte: Dados da pesquisa. Teste: Friedman ANOVA and Kendall Coeff. ofConcordance $(0,05)$

Por sua vez, as substituições ortográficas híbridas, de acordo com a Tabela 7 , foram mais frequentes nos grafemas que remetiam às consoantes fricativas, seguidos daqueles que remetiam às consoantes soantes e, em menor frequência, às consoantes oclusivas. 
Tabela 8. Distribuição das omissões

\begin{tabular}{ccccccc}
\hline Classes & $\begin{array}{c}\text { Número de } \\
\text { ocorrências }\end{array}$ & Média & Mediana & $\begin{array}{c}\text { Desvio } \\
\text { padrão }\end{array}$ & $\begin{array}{c}\text { Sum } \\
\text { ofRank }\end{array}$ & $\begin{array}{c}\text { Friedman } \\
\text { ANOVA and } \\
\text { Kendall Coeff. } \\
\text { ofConcordance }\end{array}$ \\
\hline Fricativas & 42 & 5,60 & 3,00 & 10,26 & 18,00 & $\begin{array}{c}\text { ANOVA Chi Sqr. } \\
=16,30\end{array}$ \\
Oclusivas & 206 & 27,47 & 15,00 & 50,04 & 39,50 & $\mathrm{p}=0,00$ \\
Soantes & 154 & 20,53 & 10,00 & 37,88 & 32,50 & $\mathrm{df}=2$ \\
\hline
\end{tabular}

Fonte: Dados da pesquisa. Teste: Friedman ANOVA and Kendall Coeff. ofConcordance $(0,05)$

Por fim, de acordo com a Tabela 8, as omissões foram mais frequentes nos grafemas que remetiam às consoantes oclusivas, seguidos daqueles que remetiam às consoantes soantes e às consoantes fricativas.

Observa-se que o teste inferencial se mostrou estatisticamente significativo em todos os tipos de erros, indicando que sua distribuição não ocorreu de maneira aleatória entre os grafemas que remetiam às diferentes classes consonantais.

Ressalta-se que, no interior das fricativas, as substituições mais frequentes foram as ortográficas não fonológicas e híbridas, enquanto as menos frequentes foram as substituições ortográficas fonológicas e as omissões - distribuição que se mostrou estatisticamente significativa pelo teste Friedman ANOVA and Kendall Coeff. ofConcordance (ANOVA Chi Sqr. $=37,58 ; \mathrm{p}=0,00)$. Já nas consoantes oclusivas e nas soantes, as substituições mais frequentes foram as ortográficas fonológicas, seguidas das omissões, das substituições ortográficas híbridas e das não fonológicas - distribuição também estatisticamente significativa de acordo com o teste Friedman ANOVA and Kendall Coeff. ofConcordance(Oclusivas: ANOVA Chi Sqr=19,21; $\mathrm{p}=0,00$ / Soantes: ANOVA Chi Sqr. $=26,87 ; \mathrm{p}=0,00$ ).

\section{Discussão}

Visando a uma discussão mais pontual dos resultados, partiremos da recuperação das tendências para os quais eles apontaram.

No que se refere aos resultados relativos ao primeiro objetivo que norteou a investigação, duas tendências se mostraram como estatisticamente 
significativas. A primeira delas diz respeito à (muito larga) diferença entre : a quantidade de acertos e a quantidade de erros no interior das três classes analisadas - diferença mostrada na comparação entre os números expostos nas tabelas 1 e 2 . Essa diferença sugere, de modo geral, alta estabilidade no processo de aquisição da ortografia por parte das crianças que compõem o grupo estudado. A estabilidade se mostra, sobretudo, pela distribuição não aleatória entre acertos e erros - tipo de distribuição que permite supor um movimento menos sinuoso das criançasem direção aos princípios mais gerais que governam as convenções ortográficas. Indicia-se, assim, a ação exitosa de práticas de letramento no interior das quais as crianças vão se constituindo como pequenos escreventes, bem como sua importância na alfabetização. E aqui se trata tanto daquelas práticas que, tradicionalmente, se desenvolvem em contexto escolar (certamente mais voltadas ao trabalho com as convenções ortográficas), quanto daquelas que circulam fora desse contexto, mas que, igualmente, permitem às crianças constituírem-se como escreventes.

Ainda em relação aos resultados relativos ao primeiro objetivo de nossa investigação uma segunda tendência foi detectada: a de a quantidade de acertos e de erros variar em função da classe fonológica a que remetiam os grafemas. Como o mostraram os dados expostos nas tabelas 1 e 2, os acertos se mostraram na seguinte ordem, em sentido decrescente: ortografia de consoantes oclusivas, de consoantes soantes e de consoantes fricativas. Já os erros, também em sentido decrescente, se mostraram na seguinte ordem: ortografia de consoantes fricativas; de consoantes oclusivas e de consoantes soantes.

Dada a significância dessas tendências, temos uma resposta positiva para a primeira questão que nos motivou a desenvolver a presente investigação: a relação entre acertos e erros ortográficos, na escrita infantil, varia, sim, em função da classe fonológica envolvida na correspondência grafema/fonema. Explica-se, a nosso ver, essa variação pelo fato de as classes fonológicas distinguirem-se - do ponto de vista de sua produção, de sua configuração acústica e de sua percepção - por suas características físicas. Distinguem-se, ainda, as classes por sua diferença de funcionamento na estrutura fonológica da língua. Como possivelmente essas diferenças - físicas e estruturais - não sejam homogeneamente 
salientes às crianças, a variação na distribuição dos acertos e dos erros se deve então, provavelmente, à maior/menor sensibilidade da criança a essas distintas características fonéticas e fonológicas das oclusivas, das fricativas e das soantes.

Passemos, então, às tendências detectadas nos resultados relativos ao segundo objetivo da pesquisa. Reunindo-as, a presença/ausência do acento, em si mesma, não se mostrou como diretamente favorecedora de ocorrências de erros ortográficos - como o atesta o fato de que, em termos de significância, embora os erros em sílabas não acentuadas tenham sido maiores em grafemas que remetiam a consoantes oclusivas e soantes, eles não o foram quando se tratou de consoantes fricativas. Além dessa discrepância, a distribuição de erros em função das classes fonológicas mostrou-se igual tanto em sílabas acentuadas quanto em sílabas não acentuadas, já que, em ambos os contextos, em ordem decrescente, eles se dispuseram na seguinte sequência: erros envolvendo consoantes fricativas, oclusivas e soantes. Confirma-se, então, com esses resultados, a tendência mais forte de a ocorrência de erros sofrer maior determinação do tipo de classe fonológica a que remetem os grafemas do que da presença, ou não, do acento nas sílabas das palavras. Desse modo, a segunda questão que motivou nossa investigação - o contraste entre sílabas acentuadas e não acentuadas é um fator que (des)favorece a ocorrência de erros ortográficos - não poderá receber uma resposta mais conclusiva, já que ela não pode ser nem claramente positiva, nem claramente negativa.

Passemos, por fim, à tendência mais geral detectada nos resultados relativos ao terceiro objetivo que norteou o desenvolvimento de nossa investigação: os diferentes tipos de erros (substituições ortográficas não fonológicas, fonológicas, híbridas e omissões) variaram em função da classe fonológica a que remetiam os grafemas. Podemos, então, responder positivamente à terceira questão que motivou a investigação, com a afirmação de que o tipo e a incidência dos erros também sofrem influência da classe fonológica envolvida na correspondência grafema/fonema.

Considerações mais específicas quanto à distribuição dos diferentes tipos de erros devem, no entanto, ser feitas. Inicialmente, como vimos nos dados expostos nas tabelas 5 e 7 , as substituições ortográficas não fonológicas e as híbridas foram, em primeiro plano, as que envolveram 
grafemas que remetiam à classe das consoantes fricativas. Trata-se de : tendência, de certo modo esperada: justamente esta é a classe cuja correspondência grafema/fonema mais admite diferentes possibilidades ortográficas, o que a torna a classe mais opaca no que diz respeito a essa correspondência. Desse modo, nesses dois tipos de substituições, mais as crianças se viram às voltas com as diferentes possibilidades ortográficas de um mesmo fonema do que, propriamente, com o valor fonológico dos grafemas. Bem menos opacas (ou mais transparentes) do que as possibilidades ortográficas de consoantes fricativas são as possibilidades de registro ortográfico de consoantes oclusivas e de consoantes soantes. Com efeito, das seis consoantes oclusivas do português, duas apenas ( $/ \mathrm{k} / \mathrm{e}$ $/ \mathrm{g} /$ ) admitem mais de uma possibilidade ortográfica em sua escrita. Já das sete consoantes soantes, apenas uma admite mais de uma possibilidade ortográfica, a saber, a vibrante múltipla /r/. Explica-se, então, a menor incidência de substituições ortográficas não fonológicas e híbridas entre grafemas que remetiam a fonemas dessas duas classes, bem como sua posição hierárquica - inferior em relação à das fricativas - quando se trata desses dois tipos de substituições. No entanto, como também o mostram os dados expostos nas tabelas 5 e 7, há uma diferença de posição dessas duas classes em relação às substituições ortográficas não fonológicas (maior incidência em grafemas que remetiam às consoantes oclusivas do que naqueles que remetiam às soantes) e às substituições híbridas (o inverso). Possivelmente, o fato de haver relação mais opaca na escrita de duas consoantes oclusivas (e apenas em uma consoante soante) explica a maior incidência de substituições ortográficas não fonológicas de grafemas que remetiam a essa classe. Já a maior incidência de grafemas que remetiam às consoantes soantes nas substituições ortográficas híbridas se deve, mais precisamente, às idas e voltas das crianças com a diferença de valores fonológicos do grafema $<\mathrm{r}>$, que, dependendo do contexto, ora remete à vibrante simples, ora à vibrante múltipla.

Por sua vez, os dados expostos na Tabela 6 mostram que, no que se refere às substituições ortográficas fonológicas, as substituições que remetem a consoantes fricativas foram as menos frequentes. Mais uma vez, o tipo de relação mais opaca ou mais transparente entre grafemas e fonemas permite explicar essa menor frequência, bem como a maior frequência 
desse tipo de substituição primeiramente em soantes e, em seguida em oclusivas. Pelo fato de essa relação ser bem mais opaca nas consoantes fricativas, aumentam, para as crianças, as chances de as substituições em sua escrita serem não fonológicas ou híbridas. Já o fato de essa relação ser bem mais transparente nas consoantes soantes e nas consoantes oclusivas ${ }^{6}$ faz com que aumentem significativamente as chances de uma substituição entre grafemas que remetem a elas comprometerem o aspecto fonológico da palavra escrita.

Por fim, os dados expostos na Tabela 8 mostram que as omissões foram mais frequentes em grafemas que remetiam às consoantes oclusivas, seguidas dos que remetiam às consoantes soantes e às consoantes fricativas. Acreditamos que características físicas dos fonemas dessas três classes possibilitariam explicar essa distribuição, especialmente pelo fato de, sobretudo em sua escrita inicial, as crianças guiarem-se por características perceptuais auditivas dessas consoantes (BERTI, CHACON, SANTOS, 2010; CHACON, BERTI, BURGEMEISTER, 2011; CHACON, VAZ, 2013; SCHIER, BERTI, CHACON, 2013).

Consoantes oclusivas apresentam, como principal característica motora, um bloqueio momentâneo do trato vocal, seguido de uma soltura brusca do fluxo do ar. A consequência acústica desse bloqueio é a ausência de ressonância oral (ou de energia). Já a consequência acústica da soltura brusca do fluxo de ar é a plosão, que se caracteriza por um estouro de muitíssimo curta duração, ocasionado pelo afastamento dos articuladores (KENT e READ, 1992; STEVENS, 1998). Características acústicas tão sutis, como um momento de silêncio seguido de uma brevíssima explosão podem dificultar a percepção dessas consoantes e, consequentemente, sua ortografia na escrita inicial - fato que explicaria a maior ocorrência de omissões de grafemas que remetem a fonemas dessa classe consonantal.

Diferentemente, consoantes soantes e fricativas apresentam características motoras e acústicas que - muito provavelmente - se mostrem como mais salientes para sua percepção, características que auxiliariam o estabelecimento de correspondências entre fonemas e grafemas e, portanto,

6 Nas sete consoantes que compõem a classe das soantes, apenas uma tem relação opaca com grafemas. Nas seis consoantes que compõem a classe das oclusivas, duas apenas apresentam uma relação opaca com grafemas. 
: minimizariam sua omissão na escrita infantil. Com efeito, consoantes : soantes têm como principal base de produção a vibração das cordas vocais, cujo correlato acústico é uma fonte sonora de grande energia acústica - o que as torna salientes aos ouvidos, mesmo de surdos com perdas auditivas acentuadas. Já as consoantes fricativas são produzidas por meio de um estreitamento muito acentuado dos articuladores, mas que não impede totalmente a passagem do ar pelo canal formado entre eles. O efeito acústico da passagem do ar por esse canal é, no entanto, bastante saliente, já que se caracteriza por um ruído contínuo de forte estridência nas fricativas do PB.

Essas são as possíveis explicações que encontramos para os resultados a que chegamos na investigação cujos passos foram expostos no presente artigo. Ressaltemos, porém, o que consideramos, dentre outras possíveis, como limitações dessa investigação. Uma primeira limitação é a de que ela é baseada em um grande recorte transversal de dados. Uma análise longitudinal e estendida às séries que se seguem poderia mostrar, por um lado, como gradativamente o grupo estudado chegou às características ortográficas que detectamos e, por outro, como essas características mais e mais vão se encaminhando para um domínio mais estável das convenções que regulam a correspondência fonema/grafema. Uma segunda limitação é a de que nossa análise se deteve no conjunto de fonemas de cada classe estudada. Uma análise mais minuciosa das questões ortográficas de cada fonema de cada classe poderia mostrar, por exemplo, se, além das diferenças entre as classes, também as diferenças entre seus fonemas detectaria facilidades/dificuldades mais específicas das crianças com as relações entre fonemas e grafemas. Por fim, uma análise mais específica das substituições ortográficas fonológicas poderia especificar se essas substituições, preferencialmente, se dão entre grafemas que remetem a fonemas de uma mesma classe ou entre grafemas que remetem a fonemas de distintas classes.

\section{CONSIDERAÇÕES FINAIS}

Os resultados a que chegamos com o desenvolvimento do presente estudo apontam para uma alta estabilidade na aquisição da escrita por parte do grupo estudado - portanto, para o sucesso de práticas de letramento que 
favorecem a alfabetização. Apontam, também, para relações não-simétricas entre características das classes fonológicas e a ortografia das diferentes classes - não-simetria que chama a atenção para os diferentes estatutos que tanto erros quanto acertos podem adquirir na aquisição da ortografia.

\section{REFERÊNCIAS BIBLIOGRÁFICAS}

ADAMOLI, M. A.; MIRANDA, A. R. M. Do conhecimento fonológico ao conhecimento ortográfico: as diferentes grafias dos ditongos orais mediais ai e ei em textos de escrita inicial. Cadernos de pesquisas em linguística, Porto Alegre, v. 4, p. 232-255, 2009.

AMARAL, A. S. et al. Omissão de grafemas e características da sílaba na escrita infantil. Revista CEFAC, São Paulo, v. 13, p. 846-855, 2011.

BERTI, L. C.; CHACON, L.; SANTOS, A. P. A escrita de /aN/ por préescolares: pistas acústico-auditivas. Cadernos de Educação, Pelotas, v. 19, p. 195-291, 2010.

CAMPOS, P. B. B.; TENANI, L. E.; BERTI, L. C. Os registros nãoconvencionais da coda nasal em dados de EJA. Estudos Linguísticos, São Paulo, v. 40, p. 524-538, 2011.

CARDOSO, M. H. et al. A complexidade da coda silábica na escrita de pré-escolares. Distúrbios da Comunicação, São Paulo, v. 22, p. 213-221, 2010 .

CÁRNIO, M. S. et al. Letramento escolar de estudantes de $1^{\circ}$ e $2^{2}$ séries do ensino fundamental de escola pública. Revista da Sociedade Brasileira de Fonoaudiologia, São Paulo, v. 16, n. 1, p.1-8, 2011.

CHACON, L. Para além de vínculos diretos entre características fonéticosegmentais e ortográficas na escrita infantil. Revista de Estudos da Linguagem, Belo Horizonte, v. 16, p. 215-230, 2008.

CHACON, L.; BERTI, L. C.; BURGEMEISTER, A. Ortografia da nasalidade em ataque e coda silábica na escrita infantil: características fonéticas e fonológicas. Verba Volant, Pelotas, v. 2, p. 1-21, 2011. 
: CHACON, L.; VAZ, S. Relações entre aquisição da percepção auditiva e : aprendizagem da ortografia: consoantes soantes em questão. Linguagem em (Dis)curso, Tubarão, v.13, n.3, p. 695-719, 2013.

KENT, R.; READ, C.The acoustic analysis of speech.San Diego: Singular, 1992.

KOMESU, F. C.; TENANI, L. E. A relação fala-escrita em dados produzidos em contexto digital. Scripta, Belo Horizonte, v. 13, p. 203-217, 2010.

MACHADO, M. L. C. A.; BERBERIAN, A. P.; SANTANA, A. P. Linguagem escrita e subjetividade: implicações do trabalho grupal. Revista CEFAC, São Paulo, v. 11, n.4, p. 713-719, 2009.

MASSI et al. A análise de elementos de referenciação em textos produzidos por sujeitos em processo de apropriação da escrita. Revista Distúrbios da Comunicação, São Paulo, v.21, n. 2, p. 169-178, 2009.

MIRANDA, A. R. M.; MATZENAUER, C. L. B. Aquisição da fala e da escrita: relações com a fonologia. Cadernos de Educação, Pelotas, v. 35, p. 359-405, 2010.

SCHIER, A. C.; BERTI, L. C.; CHACON, L. Desempenho perceptualauditivo e ortográfico de consoantes fricativas na aquisição da escrita. Codas, São Paulo, v.25, n.1, p.45-51, 2013.

STEVENS, K. N. Acoustic phonetics. Cambridge, MA/London: MIT Press, 1998.

TEIXEIRA, S.M. et al. Uma reflexão acerca do erro ortográfico: a importância do conhecimento sobre a língua para a prática pedagógica de professores das séries iniciais. Verba Volant, Pelotas, v. 2, p. 78-94, 2011.

TENANI, L. E.; REIS, M. C. . "E veveram felizes para sempre”: análise de grafias não-convencionais de vogais pretônicas. Verba Volant, Pelotas, v. 2, p. 22-43, 2011. 
VILLEGA, C. C. S. Hesitações em início de enunciados de crianças : em aquisição de linguagem. 2013, 84f. Dissertação (Mestrado em : Fonoaudiologia) - Faculdade de Filosofia e Ciências, Universidade Estadual Paulista "Júlio de Mesquita Filho", Marília.

\section{AGRADECIMENTOS}

Agradecemos às professoras e pesquisadoras Ana Ruth Moresco Miranda (pelas discussões que possibilitaram a criação das diferentes categorias de erros ortográficos expostas no presente artigo) e Luciani Ester Tenani (pelas discussões que resultaram na análise da relação entre omissões ortográficas e classes fonológicas). 